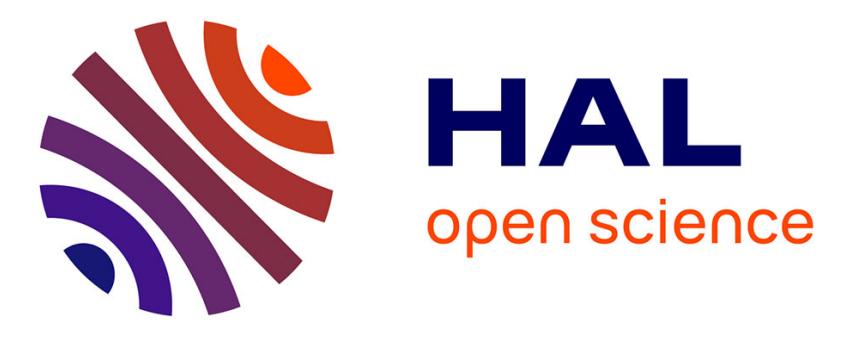

\title{
Purification of drug degradation products supported by analytical and preparative supercritical fluid chromatography
}

Angéline Noireau, Elise Lemasson, Fabien Mauge, Anne-Marie Petit, Sophie Bertin, Philippe Hennig, Éric Lesellier, Caroline West

\section{To cite this version:}

Angéline Noireau, Elise Lemasson, Fabien Mauge, Anne-Marie Petit, Sophie Bertin, et al.. Purification of drug degradation products supported by analytical and preparative supercritical fluid chromatography. Journal of Pharmaceutical and Biomedical Analysis, 2019, 170, pp.40 - 47. 10.1016/j.jpba.2019.03.033 . hal-03484432

\section{HAL Id: hal-03484432 \\ https://hal.science/hal-03484432}

Submitted on 20 Dec 2021

HAL is a multi-disciplinary open access archive for the deposit and dissemination of scientific research documents, whether they are published or not. The documents may come from teaching and research institutions in France or abroad, or from public or private research centers.
L'archive ouverte pluridisciplinaire HAL, est destinée au dépôt et à la diffusion de documents scientifiques de niveau recherche, publiés ou non, émanant des établissements d'enseignement et de recherche français ou étrangers, des laboratoires publics ou privés.

\section{(ㄷ)(1) $\$$}

Distributed under a Creative Commons Attribution - NonCommerciall 4.0 International 


\section{Purification of drug degradation products supported by analytical and 2 preparative supercritical fluid chromatography

4 Angéline Noireau a, Elise Lemasson a, Fabien Mauge ${ }^{b}$, Anne-Marie Petit c, Sophie Bertin b, Philippe

$5 \quad$ Hennig b, Éric Lesellier a, Caroline West ${ }^{*}$

a Université d'Orléans, ICOA, UMR CNRS 7311, rue de Chartres, BP 6759, 45067 Orléans cedex 2,

8 France

9 b Institut de Recherche Servier, 11 rue des Moulineaux, 92150 Suresnes, France

10 c Technologie Servier, 25/27 rue Eugène Vignat, CS 11749, 45007 Orléans cedex 1, France

*Corresponding author: Dr. Caroline West, Université d'Orléans, ICOA, UMR CNRS 7311, rue de Chartres, BP 6759, 45067 Orléans cedex 2, France. Email address: caroline.west@univ-orleans.fr

\section{ABSTRACT}

A stressed degradation (oxidation) was employed to produce metabolites from an active pharmaceutical ingredient (API) with large molecular weight (about $900 \mathrm{~g} / \mathrm{mol}$ ). An analytical chromatographic method was desired to compare the products generated by different degradation methods while a multi-gram-scale preparative chromatographic method was necessary to purify the produced metabolites. Supercritical fluid chromatography (SFC) was selected for both tasks as no other chromatographic method had achieved the resolution of the API and metabolites (two isomeric mono-oxide species and one di-oxide). First, an analytical-scale method was developed with ultra-high performance supercritical fluid chromatography (UHPSFC). Achiral stationary phases containing sub-2 $\mu \mathrm{m}$ fully porous particles or sub-3 $\mu \mathrm{m}$ superficially porous particles, and chiral phases containing 3 and $5 \mu \mathrm{m}$ fully porous particles were selected for a first screening with gradient elution (carbon dioxide methanol containing additives). The stationary phase providing the most promising results was ACQUITY Torus 2-PIC (100 × 3 mm, $1.7 \mu \mathrm{m}$, Waters). A central composite design (CCD) was conducted to optimize the gradient program and oven temperature. Final gradient conditions were as follows: 50 to $70 \%$ methanol in 3.8 min with oven temperature set at $36^{\circ} \mathrm{C}$, back-pressure set at 11 $\mathrm{MPa}$ and flow-rate at $0.8 \mathrm{~mL} / \mathrm{min}$. The optimized method was employed to analyze samples obtained with different degradation conditions. Then the method was adapted and transferred to preparativescale SFC on a $5 \mu \mathrm{m}$-particles Torus 2-PIC stationary phase $(150 \times 30 \mathrm{~mm})$. The method was modified to comprise an isocratic step followed by a gradient, favoring peak shape of the last eluting compound and minimal volume of collected fractions. Batch injections in gradient mode were carried out to purify six grams of crude product.

38 Keywords: Degradation products; Supercritical fluid chromatography; Preparative SFC; Enhanced

39 Fluidity Liquid Chromatography 
Abbreviations:

ADMET Absorption, distribution, metabolism, excretion, toxicity

Active pharmaceutical ingredient

CCD

Central composite design

DoE

Design of experiments

Enhanced fluidity liquid chromatography

EtOH

Ethanol

HPLC

High-performance liquid chromatography

iPrOH

Isopropanol

$\mathrm{MeOH}$

Methanol

\section{Introduction}

In the course of drug development, impurities, degradation products and possible metabolites [1] must be determined and purified in order to assess their toxicity for the human body. Degradation under stressed conditions are part of stability testing [2], governed by FDA and ICH guidelines [3]. The aim is to understand how a drug product will vary with time, using extreme conditions to mimic different climatic areas [4]. This degradation study may also have the purpose of producing metabolites observed in in-vivo degradations (or metabolism) when absorbing the drug, as part of the ADMET parameters (absorption, distribution, metabolism, excretion and toxicity) [5]. To identify degradation products or metabolites, high-performance liquid chromatography (HPLC) is most widely used [6]. When the degradation products and metabolites are identified, it is also necessary to obtain them in sufficient quantities for activity testing. For this purpose [7], but also to produce pure fractions for identification [8] or to generate individual enantiomers [9], preparative chromatographic techniques are most useful.

Supercritical fluid chromatography (SFC) is close to HPLC except that the main component of mobile phase is not a liquid solvent but a compressible fluid. The mobile phase composition most frequently employed in SFC is composed of a mixture of pressurized carbon dioxide [10] and a short-chain alcohol like methanol $[11,12] . \mathrm{CO}_{2}$ and the organic co-solvent may be mixed in all proportions, although most SFC applications report mobile phase compositions with a larger proportion of $\mathrm{CO}_{2}$ than co-solvent. When the proportion of solvent is larger than the proportion of carbon dioxide, the technique is often called "enhanced-fluidity liquid chromatography" (EFLC) [13]. This type of mobile phase composition was mostly employed by the group of S. Olesik, typically to analyze polar, water- 
have moderate polarity, the simple use of polar co-solvents and additives is often sufficient to achieve satisfying elution, as was already discussed by T.A. Berger long ago [17].

The principal advantages of SFC mobile phases compared to HPLC ones, are the low fluid viscosity allowing for high efficiencies at high flow rates, and the green features of $\mathrm{CO}_{2}$. D. Speybrouck and $\mathrm{E}$. Lipka even said that "greenness is not the icing on the cake but the cake itself" [18]. $\mathrm{CO}_{2}$ is recyclable, produced as a side-product from other industries, therefore has a low cost, is non-flammable and less toxic than most other solvents employed in HPLC [10]. Most of these useful characteristics are desirable, not only at the analytical scale but also at preparative scale, particularly for enantioseparations $[9,19]$. When employing small-particle fully porous (sub-2 $\mu \mathrm{m}$ ) or superficially porous (sub-3 $\mu \mathrm{m}$ ) stationary phases, combined with modern instruments offering reduced dead volumes, SFC offers comparable features to ultra-high performance liquid chromatography (UHPLC) and may be termed "ultra-high performance supercritical fluid chromatography" (UHPSFC). The separations obtained with UHPSFC have high efficiency and can be obtained very rapidly, especially as the low fluid viscosity is not causing so high pressures as in UHPLC.

In this project, the product of interest is an active pharmaceutical ingredient (API), potential future drug (stage I of development) with rather large molecular weight (about $900 \mathrm{~g} / \mathrm{mol}$ ). This product was subjected to stressful degradation, and oxidation in particular. Partial structures of the API and oxidation products can be seen in Fig. 1, to observe the position of oxidation sites relative to the while molecule. Therefore, the objective of this project was to analyze the products of stressful degradation and to obtain enough purified oxidized compounds for future activity testing. Preliminary experiments had shown that liquid chromatography (in the reversed-phase or normal-phase modes) was unsuccessful to achieve the resolution of the API from its oxidation products. Indeed, because the molecule is rather large, it was difficult to solubilize and the structural difference caused by the introduction of one or two oxygen atoms in the large molecular structure was very small and difficult to resolve. Because SFC is known to be effective in the separation of closely-related species $[20,21]$, it was investigated to achieve this task. First, an analytical method was developed to analyze samples from different degradation experiments conducted on the same active ingredient. The analytical conditions were optimized using a Design of Experiments (DoE). This chemometric approach is very useful to determine the best experimental parameters for an analysis. It allows evaluating combined interactions between parameters within a short space of time (couple hours) [22]. The optimal analytical method then needed to be adapted and scaled up to purify a few grams of the oxidized products. Robustness around the optimal conditions (+/- 1\%) was also examined to ensure a successful transfer [23].

\section{Material and methods}

2.1. Chemicals and solvents 
The API and degradation products were produced at Servier Research laboratory in Orleans, France. Their structure is confidential but their molecular weight is around $900 \mathrm{~g} / \mathrm{mol}$. Oxidative degradation with hydrogen peroxide was carried out according to $\mathrm{ICH}$ guidance [3].

At the University of Orleans, for the analytical-scale method development:

Solvents employed were HPLC-grade methanol $(\mathrm{MeOH})$, ethanol $(\mathrm{EtOH})$ and isopropyl-alcohol (iPrOH) provided by VWR (Fontenay-sous-Bois, France). Air Liquide (Paris, France) provided carbon dioxide of industrial grade $\geq 99.7 \%$. Ammonium acetate powder $\geq 98 \%$ was supplied by Merck, formic acid $\geq 99 \%$ was obtained from VWR (Fontenay-sous-Bois, France) and an Elga Purelab Flex station from Veolia (Antony, France) provided ultra-pure water.

At Servier Research laboratories, for the preparative-scale method and analysis of fractions: Solvents used were $\mathrm{MeOH}$ and $\mathrm{PrOH}$ for analysis-ACS-Reagent, provided by CARLO ERBA. Honeywell supplied methylene chloride $>99.9 \%$ (used for product dissolution). Ammonium acetate (>98\%) was obtained from ACROS and formic acid (> 98\%) from Merck. Messer provided carbon dioxide ( $\geq 99.995 \%$ ) and ultra-pure water was obtained with a MiliQ® - Advantage A10 system.

\subsection{Instrumentation}

\subsubsection{UHPSFC system}

The analytical system used for analytical method development and analysis of fractions was an ACQUITY Ultra Performance Convergence Chromatography ${ }^{\mathrm{TM}}$ (UPC ${ }^{2}{ }^{\circledR}$ ) from Waters Corporation (Milford, MA, USA). It was equipped with a binary solvent delivery pump, compatible with mobile phase flow rates up to $4 \mathrm{~mL} / \mathrm{min}$ and pressures up to 414 bar. The system had an autosampler that included partial loop volume injection system, a backpressure regulator and 2-position column oven compatible with $150 \mathrm{~mm}$ length columns. Two detectors were available: a photodiode-array (PDA) detector and an ACQUITY QDa ${ }^{\circledR}$ single-quadrupole mass spectrometric (MS) detector with electrospray ionization source (ESI). An isocratic solvent manager was used as a make-up pump and was positioned before the mass detector. The main flow stream was then split by the on-board-flowsplitter assembly. With this system, a portion of the column flow goes to the backpressure regulator and another (unknown) portion goes to the mass detector. Empower ${ }^{\circledR} 3$ software was used for system control and data acquisition.

\subsubsection{Preparative-scale SFC system}

An SFC-PICLab PREP 200 from PIC Solution ${ }^{\mathrm{TM}}$ (Avignon, France) was employed for the purification of oxidation products. It was a $200 \mathrm{ml} / \mathrm{min}$ preparative SFC system designed for 20 and $30 \mathrm{~mm}$ i.d. columns. It could stand up to 350 bar and host five columns (or four columns plus bypass). Thanks to a recycling system, and depending on co-solvent percentage, $\mathrm{CO}_{2}$ should be retrained in supercritical conditions (for instance, more than $95 \%$ of $\mathrm{CO}_{2}$ is recycled with $10 \%$ of co-solvent). The system had 
five collection tracks, of which one served for waste. SFC PICLAB PREP ONLINE was the software used for system control and data acquisition.

\subsection{Stationary phases}

In order to determine a stationary phase to achieve the best resolution of API and degradation products, fifteen commercial columns were selected: six chiral and nine achiral stationary phases. Their characteristics are gathered in Table 1. Waters (Guyancourt, France), Phenomenex (Le Pecq, France) Supelco, Thermo Fisher Scientific (Villebon, France), Macherey-Nagel (Hoerdt, France) and Chiral Technologies (Illkirch-Graffenstaden, France) kindly provided the columns.

\subsection{Chromatographic conditions}

The screening of the different columns was performed with a large elution gradient from 10 to $100 \%$ of co-solvent in $\mathrm{CO}_{2}$ in $15 \mathrm{~min}$. Indeed, because the API and oxidation products were strongly retained, it was necessary to elevate the proportion of co-solvent to a high percentage to elute them from the columns. The co-solvent was $\mathrm{MeOH}$ containing $2 \%$ pure water and $20 \mathrm{mM}$ ammonium acetate (AA). This mobile phase composition was previously defined as being most favorable to the elution of drug candidates with good peak shapes, along with good ESI-MS response [24]. The flow rate was set at $0.5 \mathrm{~mL} / \mathrm{min}$ with sub- $2 \mu \mathrm{m}$ columns and $1 \mathrm{~mL} / \mathrm{min}$ with other column dimensions, to avoid reaching the upper pressure limit before the end of the gradient program. Temperature was set at $25^{\circ} \mathrm{C}$ and the outlet pressure was fixed at $15 \mathrm{MPa}$.

Samples were prepared at $1 \mathrm{mg} / \mathrm{mL}$ in methanol and $2 \mu \mathrm{L}$ were injected. The wavelength of UV detection was set at $210 \mathrm{~nm}$, with frequency set at $20 \mathrm{pts} / \mathrm{s}$ and resolution at $1.2 \mathrm{~nm}$.

The mass detector unit was pre-optimized by the manufacturer. Ion source temperature was fixed at $120^{\circ} \mathrm{C}$, probe temperature at $600^{\circ} \mathrm{C}$, scan rate at $8 \mathrm{pts} / \mathrm{s}$, capillary voltage at $0.8 \mathrm{kV}$, cone voltage at $15 \mathrm{~V}$ and sampling frequency at $8 \mathrm{~Hz}$. Nebulizing gas was nitrogen. The make-up solvent composition was $98 \% \mathrm{MeOH}, 2 \%$ pure water plus $1 \%$ formic acid with a $0.45 \mathrm{~mL} / \mathrm{min}$ flow. The analytes were detected in positive and negative electrospray ionization mode ( $\mathrm{m} / \mathrm{z} 400-1000)$.

\subsection{Mobile phase optimization}

After selecting the best stationary phase from the screening experiments (ACQUITY Torus 2-PIC), a central composite design (CCD) was conducted to optimize the gradient program. Flow-rate was set at $0.8 \mathrm{~mL} / \mathrm{min}$ and backpressure at $11 \mathrm{MPa}$ in order to not generate system overpressure. Because three analytical parameters had to vary (final co-solvent percentage, gradient time and oven temperature), the CCD contains a factorial design with $2^{3}=8$ points (angles of the cube), six star points and a central point with six replicates to assess the experimental error. The distance between the center of the design space and a factorial point was \pm 1 unit whereas the distance between the center of the design space and a star point is $\alpha=2^{3 / 4}=1.682$ with $\alpha$ is the isovariance criterion by rotation [25]. Therefore, 
each of the three analytical parameters was explored at five levels: $-1.682 ;-1 ; 0 ;+1 ;+1.682$ (see Table 2). The software used to assist in this work was $\mathrm{JMP}^{\circledR}$ trial version, (S.A.S Institute Inc, Cary, NC, USA).

Judging from the screening experiments, the initial co-solvent percentage was fixed at $50 \%$. Again this unusual initial percentage is due to the high molecular weight $(\sim 900 \mathrm{~g} / \mathrm{mol})$ of the API and degradation product. Overall, 20 experiments were conducted, in a random order generated by the software.

\section{Optimum calculation:}

For each experiment, the separation criterion $(S)$ was used (instead of resolution) to assess the separation quality of two successive peaks [26]. It is defined as the difference between the retention time at the beginning of the $n+1$ peak $\left(t_{B} n+1\right)$ and the retention time at the end of the $n$ peak ( $\left.t_{E} n\right)$. Peaks are baseline resolved if $S$ is positive.

When the optimal point was found, because the result was still not considered sufficiently good, the separation was further improved with the modification of co-solvent nature ( $\mathrm{MeOH}$ and $\mathrm{PrOH})$. The final mobile phase co-solvent was $\mathrm{MeOH}-\mathrm{iPrOH}$ 70:30 (v/v), comprising $20 \mathrm{mM}$ ammonium acetate and $2 \%$ water.

Then, the robustness in optimized conditions was explored with variations of each of the three optimized parameters (final solvent percentage, gradient time, temperature) of more or less $1 \%$. Thus six additional experiments were done to assess the changes caused by small variations around the optimal point. The experiments and results are presented in Tables S1 and S2, in supplementary material.

The SFC-PICLab PREP 200 was used to purify the active pharmaceutical ingredient (API) from its oxidized degradation products. ACQUITY UPC 2 Torus 2-PIC column (150 x $30 \mathrm{~mm}, 5 \mu \mathrm{m})$ was employed and the mobile phase composition was the one optimized at the analytical scale. In preparative SFC, stacked injection in isocratic elution mode is preferred to increase productivity [9]. In addition, the lowest proportion of solvent is desirable to limit solvent consumption and evaporation time. Therefore, methods in isocratic elution mode were also tested with $40 \%, 45 \%, 50 \%, 55 \%$ and $60 \%$ of co-solvent. It turned out that a rather good separation with poor peak shapes were obtained with $45 \%$ of co-solvent in 15 minutes. However, in the present case, the last peak (di-oxidized compound) showed a significantly tailing peak, probably due to the low solubility of this compound. In order to improve the peak shape and minimize the volume of collected fractions for this peak, a 
second gradient program was designed, which prevented the use of stacked injections. First, the program included an isocratic step with $45 \%$ co-solvent during $10 \mathrm{~min}$. Then, the co-solvent proportion was raised to $65 \%$ in $1 \mathrm{~min}$ and maintained during $5 \mathrm{~min}$ to ensure the elution of the last compound. Thanks to high diffusivities in the mobile phase, due to the presence of a large portion of pressurized carbon dioxide, the column was reconditioned at $45 \%$ for only $4 \mathrm{~min}$ before the next injection. Cycle time was then $18.1 \mathrm{~min}$. The flow rate was set at $100 \mathrm{~mL} / \mathrm{min}$, oven temperature at $40^{\circ} \mathrm{C}$, outlet pressure at $10 \mathrm{MPa}$ and UV detection at $210 \mathrm{~nm}$. Six grams of crude product were dissolved in $15 \mathrm{~mL}$ methylene chloride. The injection volume was $300 \mu \mathrm{L}$; the injection lasted $10 \mathrm{~s}$.

\section{Fractions quality control:}

The solvent from the collected fractions was evaporated with a rotary evaporator and the dry residue was weighted. For purity analysis, ACQUITY UPC² system was used with Acquity Torus 2-PIC $(150 \times 4.6 \mathrm{~mm}, 5 \mu \mathrm{m})$ column. The mobile phase was the same as used for compounds purification. The elution gradient profile was: $55 \%$ co-solvent from 0 to $5 \mathrm{~min}$, then an increase to $70 \%$ from 5 to 10 min and finally re-equilibration at $55 \%$ in $0.1 \mathrm{~min}$ for a $12 \mathrm{~min}$ total run. Flow rate was $2.5 \mathrm{~mL} / \mathrm{min}$, oven temperature was fixed at $35^{\circ} \mathrm{C}$ and a volume of $3 \mu \mathrm{L}$ was injected. Detection wavelength was set at $290 \mathrm{~nm}$ (instead of $210 \mathrm{~nm}$ ) because no baseline drift appeared at this wavelength when increasing co-solvent percentage from $55 \%$ to $70 \%$. Mass detection was carried out by the $\mathrm{QDa}^{\circledR}$ with the same previous settings except for the mass range (from 150-700 m/z). Make-up solvent for mass analysis was $\mathrm{MeOH} /$ water (90/10) $\mathrm{v} / \mathrm{v}$ with $0.1 \%$ formic acid. Flow rate was $0.5 \mathrm{~mL} / \mathrm{min}$.

\section{Results and discussion}

\subsection{Stationary phase selection}

Fifteen columns were selected for the initial screening (Table 1). Stationary phases with small particle size (fully porous sub-2 $\mu \mathrm{m}$ or superficially porous $3-\mu \mathrm{m}$ ) were favored, apart from some chiral phases that were not available with such dimensions. Although no chirality is involved in the desired separation, both achiral and chiral stationary phases were selected, as chiral phases are also interesting to separate analytes with small structural differences [27]. The columns selected cover a wide range of selectivities, primarily for polar-type interactions as the separation process should target the number and position of oxygen atoms from the oxidation process. Indeed, it was expected that positional isomers of oxidation products would be produced by the forced degradation. The diversity of selectivities in the chosen columns can be observed from the spider diagram [28] in Figure 2.

The aim of this first screening step was to find one stationary phase that would provide the best separation of the API and all degradation products while maintaining a percentage of co-solvent as low as possible. Indeed, while a large proportion of co-solvent is not causing any issue at the analytical scale, it is not desirable for preparative-scale to have a large proportion of co-solvent because the solvent consumption and waste would rise, and the volume of solvent to evaporate from collected fractions would be unreasonable and time-consuming. At this stage, both UV and mass 
spectrometric (MS) detection were employed: UV served at observing resolution between all species in the samples while MS served at identifying the target analytes (API and oxidation products). Indeed, no standard was available to compare to the samples, so the MS spectra were examined. In addition,

283

284

285

286

287

288

289

290

291

292

293

294

295

296

297

298

299

300

301

302

303

304

305

306

307

308

309

310

311

312

313

314

315

316

317

318 the UV chromatograms shows additional peaks that need not be purified.

To compare the fifteen different stationary phases, a gradient elution running from 10 to $100 \%$ cosolvent was employed. This wide gradient thus comprises the usual domains of SFC and EFLC. The API elution composition $\left(\mathrm{C}_{\mathrm{e}}\right)$ was calculated according to Eq. 2 and corresponds to the co-solvent percentage required to elute the compound of interest [29] .

$C_{e}=C_{i}+\frac{\left(C_{f}-C_{i}\right)}{t_{G}} *\left(t_{R}-t_{D}\right)$

$\mathrm{C}_{\mathrm{i}}$ and $\mathrm{C}_{\mathrm{f}}$ are respectively the initial and final compositions of the gradient, $t_{G}$ is the gradient time, $t_{R}$ is the retention time of the compound and to is the system dwell time ( $0.46 \mathrm{~min}$ in our case).

As a result of the columns screening (chromatograms in electronic supplementary information, Figure S1), with gradient conditions from 10 to $100 \%$ co-solvent, all columns yielding excessive retention (elution composition of API above 50\% co-solvent) were excluded: Acquity UPC ${ }^{2}$ HSS C18 SB, Kinetex HILIC, Accucore HILIC, Accucore Amide HILIC, Accucore Urea HILIC, Ascentis Express OH5, Chiralpak IA, IB, IC, ID, IF and IG. The oxidation products were all more retained than the API, and sometimes some of them did not elute at all.

The next step was to look at the number of detected peaks and the separation quality. At this stage, Ascentis Express F5 was excluded because the peaks were broad. ACQUITY UPC2 Torus 2-PIC from Waters and Nucleoshell HILIC from Macherey-Nagel were the two stationary phases promising the best results in terms of separation optimization (this is visible in the UV chromatograms in electronic supplementary information, Figure S1). However, the gradient profile was not satisfactory with the Nucleoshell HILIC column because the ammonium acetate breakthrough curve caused a bump in the baseline that happened at the same time as one target peak. Indeed, the additives (ammonium acetate, water) are present at a low but increasing concentration in the mobile phase. At the beginning of the gradient, the additives adsorb on the stationary phase as any other mobile phase component. When the stationary phase is saturated with additives, a small breakthrough curve is visible in the baseline (gradient slope). On stationary phases where ionic interactions are strong (as is the case on the sulfobetaine ligand in Nucleoshell HILIC column), the sudden rise of ammonium acetate concentration in the mobile phase is usually causing the grouped elution of ionic analytes, causing a loss of resolution. Also, because of the highest concentration of ammonium acetate at this moment, it is undesirable to collect a fraction at that time, thus the ACQUITY UPC 2 Torus 2-PIC was retained as the best column. Moreover, it was important that the selected column was available at preparative scale. 
Twenty experiments were conducted according to the design of experiments (DoE) described in experimental section to generate optimal gradient and temperature conditions. The whole set of DoE experiments lasted around four hours, taking into account the column equilibration time. The best resolution was desired, together with narrow and symmetric peaks. At the preparative scale, thin and symmetric peaks essentially mean that the time window for fraction collection will be the lowest possible, thereby ensuring more concentrate fractions and less solvent to evaporate to obtain the dry product. Good resolution will also mean that the purity of the fractions collected shall be high. The chromatogram in Fig. 3 represents the separation between the API and degradation products in optimal analytical conditions determined by the DoE. The analytes were identified with the assistance of ESI-MS detection. The first peak, with a 2 minutes retention time, was not interesting for this project so it will not be further discussed. The second peak corresponded to the active pharmaceutical ingredient with a molecular weight (M) near $\mathrm{M} \sim 900 \mathrm{~g} / \mathrm{mol}$. The third and fourth peaks were isomeric mono-oxidized degradation products with $\mathrm{M}+16$ molecular weight. The last peak had a $\mathrm{M}+32$ molecular weight, corresponding to a di-oxidized degradation product.

To generate optimal conditions, five responses were selected and taken into account in the software. Four separation criterions (S), calculated according to Eq. (1), in order to assess the separation quality between the five main peaks, and the asymmetry of the last eluted peak, because it tended to tail significantly.

340 For each of the five responses, desirability was defined. The highest $S$ value was desired for the four $S$ criterions. For asymmetry criterion, we wanted values the closest to one. For example, iso-response graphs are presented in Fig. 4 for the critical pair of peaks ( 3 and 4 ) corresponding to the two monooxidized degradation products. These graphs allowed to model the DoE response: temperature vs. final proportion of co-solvent (on the left) and temperature vs. gradient time (on the right). The darkest area corresponds to a response zone where desirability is maximum. The crossing of the dashed black lines represents optimal values (normalized values) determined by DoE. On this figure, it appears that the overall optimum (defined by crossed interrupted lines) is not necessarily the same as the local optimum for each pair of consecutive peaks. The overall optimum is therefore a compromise to satisfy all five responses.

Optimal elution gradient conditions were found as follows: from 50 to $70.3 \%$ co-solvent (corresponding to the normalized value 0.052 ) in 3.8 minutes (normalized value -1 ) with oven temperature set at $36^{\circ} \mathrm{C}$ (normalized value +1 ).

\section{Modification of co-solvent nature:}

356 After the elution gradient optimization with $\mathrm{MeOH}$ containing $20 \mathrm{mM} \mathrm{AA}$ and $2 \%$ water as co-solvent, 357 the two mono-oxide peaks were not sufficiently resolved to hope for a productive purification (Fig. 3). 358 Therefore, it was decided to modify the mobile phase composition, introducing a portion of isopropyl- 
alcohol (iPrOH). This solvent is less polar than $\mathrm{MeOH}$ and caused increased retention and separation factors (Fig. 5). A MeOH / iPrOH 70/30 (v/v) mixture was finally selected as a middle ground between separation quality, peak shape and run time. The final conditions for this analytical method may not be SFC, but they may be EFLC.

The robustness of the method was assessed as described in experimental section and supplementary material (Tables S1 and S2). It was observed that all parameters observed (retention time, peak area, asymmetry and resolution) remained stable within $2 \%$.

The method then served to compare different samples obtained after different conditions of stressed degradation applied to the same API, prior to scale-up.

\subsection{Method transfer to preparative-scale}

The optimal SFC (or EFLC) method determined at the previous step was transferred to the preparative scale as described in the experimental section. Four fractions were collected: the API from 5.47 to $6.67 \mathrm{~min}$, two mono-oxidized degradation products from 6.83 to $8.3 \mathrm{~min}$ and from 9.2 to $10.7 \mathrm{~min}$ and one di-oxidized degradation product from 11.92 to $15.43 \mathrm{~min}$ (Fig. 6). The whole purification experiments lasted nearly 20 hours. Overall, $60 \mathrm{~L}$ of solvent and $57 \mathrm{~L}$ of carbon dioxide were eluted through the system. Actually, the $\mathrm{CO}_{2}$ consumption was much less than $57 \mathrm{~L}$ thanks to the recycling system implemented. According to PIC Solution ${ }^{\mathrm{TM}}$, more than $90 \%$ of $\mathrm{CO}_{2}$ is recycled with $10 \%$ of cosolvent and $85 \%$ is recycled with $30 \%$ of co-solvent. We may thus expect that a lower proportion of $\mathrm{CO}_{2}$ would be recycled in the present conditions. The collected volumes and masses of dry product obtained for each fraction are indicated in Table 3. Obviously, the volume of solvent collected for the fourth peak (di-oxidized product) is much larger than the others, due to (i) large proportion of this compound in the sample injected and (ii) large proportion of co-solvent in this section of the chromatogram, to elute this peak with reasonably short time frame. It is important to note that such large proportions of solvent are quite unusual for SFC, but were necessary here to separate and elute these high-molecular weight products. In terms of productivity, $306 \mathrm{mg}$ of product were purified in an hour for an average co-solvent consumption of 3 liters. For example, the purified mass is 14 times that of the product purified in a paper from E. Landagaray et al. [22], but it is also 14 times more solvent consuming. In terms of productivity, we have purified about $0.1 \mathrm{~kg}$ product per $\mathrm{kg}$ of stationary phase per day (kkd), which may be compared to about $0.2 \mathrm{kkd}$ in ref. [22]. While $0.1 \mathrm{kkd}$ is by no means an exceptional productivity, it may however be considered reasonably good [18], especially judging from the difficulty in the separation and the fact that three compounds needed to be collected among other undesirable species. If larger quantities had been desired, further optimization could have been done (flow rate, injected mass and volume, dilution solvent, etc.).

\subsection{Fractions analysis}


Each fraction was analyzed in order to verify the quality of purified compounds. The results are summarized in Table 3. We noticed that the API collection (fraction 1) was pure at $98.5 \%$ whereas for the mono-oxidized degradation products (fractions 2 and 3 ), the presence of di-oxidized compound (eluted later) was detected up to $2.6 \%$. It was not a problem because the desired purity level of monooxidized compounds was achieved (95.8\% and $97.5 \%)$. The presence of di-oxidized compound in these two fractions may result from further oxidation occurring after the preparative chromatography, perhaps at the evaporation stage but this hypothesis was not verified.

\section{Conclusions}

Supercritical fluid chromatography at analytical-scale was used to solve the issue in degradation products separation, emerged throughout first trials in HPLC. Thanks to this technique, three degradation products (two isomeric mono-oxidized and one di-oxidized) were isolated from the API. The fast and broad screening of stationary phases and design of experiments quickly provided an optimal analytical method. Because of the large molecular weight of the analytes, inducing limited solubility and strong interactions with the stationary phase, unusual SFC conditions were necessary to obtain this separation, with co-solvent percentage in carbon dioxide up to $70 \%$, which is probably more relevant of enhanced-fluidity liquid chromatography (EFLC). Contrary to some previous reports from Miller and Potter [30], scale-up from ultra-high performance chromatographic conditions to preparative SFC was quite straightforward in this case and allowed efficient purification of all degradation products for further activity testing.

\section{Conflicts of interest}

The authors declare no conflicts of interest.

\section{Acknowledgments}

Waters Corporation is warmly thanked for the support received at the University of Orleans through the Centers of Innovation program. We also thank Régis Guyon (Macherey-Nagel), Dave Bell (formerly at Sigma-Aldrich), Magali Dupin and Marc Jacob (Phenomenex), Thierry Domenger (Thermo) and Pilar Franco (Chiral Technologies) for the kind gift of columns. 


\section{References}

433

[1] ICH Guidelines, Q3A \& B (R2) : Impurities in new drug products and impurities in new drug substances, (2006). https://www.ich.org/products/guidelines/quality/article/quality-guidelines.html.

[2] S. Singh, M. Junwal, G. Modhe, H. Tiwari, M. Kurmi, N. Parashar, P. Sidduri, Forced degradation studies to assess the stability of drugs and products, TrAC Trends in Analytical Chemistry. 49 (2013) 71-88. doi:10.1016/j.trac.2013.05.006.

[3] ICH guidelines, Q1A (R2): Stability testing of new drug substances and products, (2003). https://www.ich.org/products/guidelines/quality/article/quality-guidelines.html.

[4] M. Blessy, R.D. Patel, P.N. Prajapati, Y.K. Agrawal, Development of forced degradation and stability indicating studies of drugs-A review, Journal of Pharmaceutical Analysis. 4 (2014) 159165. doi:10.1016/j.jpha.2013.09.003.

[5] B.S. Kushwah, J. Gupta, D.K. Singh, M. Kurmi, A. Sahu, S. Singh, Characterization of solution stress degradation products of aliskiren and prediction of their physicochemical and ADMET properties, European Journal of Pharmaceutical Sciences. 121 (2018) 139-154. doi:10.1016/j.ejps.2018.05.021.

[6] D.K. Singh, A. Sahu, S. Kumar, S. Singh, Critical review on establishment and availability of impurity and degradation product reference standards, challenges faced by the users, recent developments, and trends, TrAC Trends in Analytical Chemistry. 101 (2018) 85-107. doi:10.1016/j.trac.2017.10.021.

[7] G. Guiochon, Preparative liquid chromatography, Journal of Chromatography A. 965 (2002) 129161. doi:10.1016/S0021-9673(01)01471-6.

[8] C. Berger, M. Perrut, Preparative supercritical fluid chromatography, Journal of Chromatography A. 505 (1990) 37-43. doi:10.1016/S0021-9673(01)93067-5.

[9] L. Miller, Preparative enantioseparations using supercritical fluid chromatography, J Chromatogr A. 1250 (2012) 250-255. doi:10.1016/j.chroma.2012.05.025.

[10] Packed Column Sub-and Supercritical Fluid Chromatography, in: Analytical Separation Science, Wiley-VCH, Jared L. Anderson, Alain Berthod, Veronica Pino and Apryll M. Stalcup, 2015: pp. $1051-1074$.

[11] E. Lesellier, C. West, The many faces of packed column supercritical fluid chromatography - A critical review, J Chromatogr A. 1382 (2015) 2-46. doi:10.1016/j.chroma.2014.12.083.

[12] C. West, Current trends in supercritical fluid chromatography, Analytical and Bioanalytical Chemistry. 410 (2018) 6441-6457. doi:10.1007/s00216-018-1267-4.

[13] Beres Martin J., Olesik Susan V., Enhanced-fluidity liquid chromatography using mixed-mode hydrophilic interaction liquid chromatography/strong cation-exchange retention mechanisms, $J$ Sep Sci. 38 (2015) 3119-3129. doi:10.1002/jssc.201500454.

[14] Susan V. Olesik, Enhanced-Fluidity Liquid Chromatography: Connecting the Dots Between Supercritical Fluid Chromatography, Conventional Subcritical Fluid Chromatography, and HPLC, LC-GC North America. 33 (2015) 24-30.

[15] J.W. Treadway, G.S. Philibert, S.V. Olesik, Enhanced fluidity liquid chromatography for hydrophilic interaction separation of nucleosides, J. Chromatogr. A. 1218 (2011) 5897-5902. doi:10.1016/j.chroma.2010.12.059.

[16] R. Bennett, S.V. Olesik, Protein separations using enhanced-fluidity liquid chromatography, Journal of Chromatography A. 1523 (2017) 257-264. doi:10.1016/j.chroma.2017.07.060.

[17] T.A. Berger, Separation of polar solutes by packed column supercritical fluid chromatography, J. Chromatogr. A. 785 (1997) 3-33. doi:10.1016/S0021-9673(97)00849-2.

[18] D. Speybrouck, E. Lipka, Preparative supercritical fluid chromatography: A powerful tool for chiral separations, J Chromatogr A. 1467 (2016) 33-55. doi:10.1016/j.chroma.2016.07.050.

[19] G. Guiochon, A. Tarafder, Fundamental challenges and opportunities for preparative supercritical fluid chromatography, J. Chromatogr. A. 1218 (2011) 1037-1114. doi:10.1016/j.chroma.2010.12.047.

[20] E.L. Regalado, P. Zhuang, Y. Chen, A.A. Makarov, W.A. Schafer, N. McGachy, C.J. Welch, Chromatographic Resolution of Closely Related Species in Pharmaceutical Chemistry: Dehalogenation Impurities and Mixtures of Halogen Isomers, Anal. Chem. 86 (2014) 805-813. doi:10.1021/ac403376h.

[21] C. Gourmel, A. Grand-Guillaume Perrenoud, L. Waller, E. Reginato, J. Verne, B. Dulery, J.-L. Veuthey, S. Rudaz, J. Schappler, D. Guillarme, Evaluation and comparison of various separation techniques for the analysis of closely-related compounds of pharmaceutical interest, J. Chromatogr. A. 1282 (2013) 172-177. doi:10.1016/j.chroma.2013.01.095. 
[22] E. Landagaray, C. Vaccher, S. Yous, E. Lipka, Design of experiments for enantiomeric separation in supercritical fluid chromatography, J Pharm Biomed Anal. 120 (2016) 297-305. doi:10.1016/j.jpba.2015.12.041.

[23] A. Dispas, P. Lebrun, B. Andri, E. Rozet, P. Hubert, Robust method optimization strategy-A useful tool for method transfer: The case of SFC, J. Pharm. Biomed. Anal. 88 (2014) 519-524. doi:10.1016/j.jpba.2013.09.030.

[24] E. Lemasson, S. Bertin, P. Hennig, H. Boiteux, E. Lesellier, C. West, Development of an achiral supercritical fluid chromatography method with ultraviolet absorbance and mass spectrometric detection for impurity profiling of drug candidates. Part I: Optimization of mobile phase composition, J Chromatogr A. 1408 (2015) 217-226. doi:10.1016/j.chroma.2015.07.037.

[25] L. Ferey, A. Raimbault, I. Rivals, K. Gaudin, UHPLC method for multiproduct pharmaceutical analysis by Quality-by-Design, Journal of Pharmaceutical and Biomedical Analysis. 148 (2018) 361-368. doi:10.1016/j.jpba.2017.10.014.

[26] P. Lebrun, B. Govaerts, B. Debrus, A. Ceccato, G. Caliaro, P. Hubert, B. Boulanger, Development of a new predictive modelling technique to find with confidence equivalence zone and design space of chromatographic analytical methods, Chemometrics and Intelligent Laboratory Systems. 91 (2008) 4-16. doi:10.1016/j.chemolab.2007.05.010.

[27] E.L. Regalado, C.J. Welch, Separation of achiral analytes using supercritical fluid chromatography with chiral stationary phases, TrAC Trends in Anal Chem. 67 (2015) 74-81. doi:10.1016/j.trac.2015.01.004.

[28] C. West, E. Lesellier, A unified classification of stationary phases for packed column supercritical fluid chromatography, J. Chromatogr. A. 1191 (2008) 21-39. doi:10.1016/j.chroma.2008.02.108.

[29] E. Lemasson, S. Bertin, P. Hennig, E. Lesellier, C. West, Comparison of ultra-high performance methods in liquid and supercritical fluid chromatography coupled to electrospray ionization - mass spectrometry for impurity profiling of drug candidates, J Chromatogr A. 1472 (2016) 117-128. doi:10.1016/j.chroma.2016.10.045.

[30] L. Miller, M. Potter, Preparative chromatographic resolution of racemates using HPLC and SFC in a pharmaceutical discovery environment, J. Chromatogr. B. 875 (2008) 230-236. doi:10.1016/j.jchromb.2008.06.044. 
Fig. 1. Partial structures of the API and oxidation products examined in this study.

Fig. 2. Linear Solvation Energy Relationships (LSER) classification showing the 15 tested columns (achiral stationary phases in blue and enantioselective stationary phases in purple).

Fig. 3. Chromatogram of the sample from forced degradation obtained on Acquity Torus 2-PIC column $(100 \times 3.0 \mathrm{~mm}, 1.7 \mu \mathrm{m})$ with the optimal elution gradient conditions as defined by the DoE: $100 \%$ $\mathrm{MeOH}$ co-solvent $+20 \mathrm{mM} \mathrm{AA}+2 \%$ water in mobile phase; gradient elution as indicated in the figure. UV detection $210 \mathrm{~nm}$. Red star is the API (M); blue diamonds are the two isomeric mono-oxide species $(M+16)$; green circle is the di-oxidized degradation product $(M+32)$.

Fig. 4. Iso-response graphs of separation criterion $S$ for the critical pair of peaks (peaks 3 and 4). The crossing of the dashed black lines represents optimal values of the DoE.

Fig. 5. Chromatogram of the sample from forced degradation obtained on Acquity Torus 2-PIC column $(100 \times 3.0 \mathrm{~mm}, 1.7 \mu \mathrm{m})$ with optimal elution gradient and modified mobile phase composition: cosolvent $70 \% \mathrm{MeOH} / 30 \%$ iPrOH comprising $20 \mathrm{mM} \mathrm{AA}+2 \%$ water in mobile phase; gradient elution as indicated in the figure. UV detection $210 \mathrm{~nm}$. Red star is the API (M); blue diamonds are the two isomeric mono-oxide species $(M+16)$; green circle is the di-oxidized degradation product $(M+32)$.

Fig. 6. Fraction collection (purple areas) in preparative supercritical fluid chromatography with elution gradient profile (green line). Separation done with Torus 2-PIC column (150 x $30 \mathrm{~mm}, 5 \mu \mathrm{m})$ and mobile phase co-solvent comprising $70 \% \mathrm{MeOH}$ and $30 \% \mathrm{iPrOH}$ comprising $2 \%$ water and $20 \mathrm{mM}$ ammonium acetate. UV detection $210 \mathrm{~nm}$. 
Table 1

550 The 15 columns used to screen the samples in this study

\begin{tabular}{|c|c|c|c|c|c|}
\hline Column Name & Manufacturer & Particle type & Bonded ligand & $\begin{array}{l}\text { Dimensions } \\
(\mathrm{mm})\end{array}$ & $\begin{array}{l}\text { Particle } \\
\text { size }(\mu \mathrm{m})\end{array}$ \\
\hline $\begin{array}{l}\text { ACQUITY } \\
\text { UPC² Torus 2- } \\
\text { PIC }\end{array}$ & Waters & $\begin{array}{l}\text { Fully porous } \\
\text { hybrid silica }\end{array}$ & 2 Picolyl-amine & $100 \times 3.0$ & 1.7 \\
\hline $\begin{array}{l}\text { ACQUITY } \\
\text { UPC }{ }^{2} \text { HSS C18 } \\
\text { SB }\end{array}$ & Waters & $\begin{array}{l}\text { Fully porous high } \\
\text { strength silica }\end{array}$ & Octadecyl, non endcapped & $100 \times 3.0$ & 1.8 \\
\hline Kinetex HILIC & Phenomenex & $\begin{array}{l}\text { Superficially } \\
\text { porous silica }\end{array}$ & - & $150 \times 4.6$ & 2.6 \\
\hline Accucore HILIC & Thermo & $\begin{array}{l}\text { Superficially } \\
\text { porous silica }\end{array}$ & - & $150 \times 4.6$ & 2.6 \\
\hline $\begin{array}{l}\text { Accucore } \\
\text { Amide-HILIC }\end{array}$ & Thermo & $\begin{array}{l}\text { Superficially } \\
\text { porous silica }\end{array}$ & - & $150 \times 4.6$ & 2.6 \\
\hline $\begin{array}{l}\text { Accucore Urea- } \\
\text { HILIC }\end{array}$ & Thermo & $\begin{array}{l}\text { Superficially } \\
\text { porous silica }\end{array}$ & - & $150 \times 4.6$ & 2.6 \\
\hline $\begin{array}{l}\text { Ascentis } \\
\text { Express } \mathrm{OH} 5\end{array}$ & Supelco & $\begin{array}{l}\text { Superficially } \\
\text { porous silica }\end{array}$ & Penta-hydroxyl & $150 \times 4.6$ & 2.7 \\
\hline $\begin{array}{l}\text { Ascentis } \\
\text { Express F5 }\end{array}$ & Supelco & $\begin{array}{l}\text { Superficially } \\
\text { porous silica }\end{array}$ & Penta-fluorophenyl & $150 \times 4.6$ & 2.7 \\
\hline $\begin{array}{l}\text { Nucleoshell } \\
\text { HILIC }\end{array}$ & Macherey-Nagel & $\begin{array}{l}\text { Superficially } \\
\text { porous silica }\end{array}$ & Sulfobetaine & $150 \times 3.0$ & 2.7 \\
\hline Chiralpak IA & $\begin{array}{l}\text { Chiral } \\
\text { Technologies }\end{array}$ & $\begin{array}{l}\text { Fully porous } \\
\text { silica }\end{array}$ & $\begin{array}{l}\text { Amylose tris-(3,5- } \\
\text { dimethylphenylcarbamate) }\end{array}$ & $150 \times 4.6$ & 3.0 \\
\hline Chiralpak IB & $\begin{array}{l}\text { Chiral } \\
\text { Technologies }\end{array}$ & $\begin{array}{l}\text { Fully porous } \\
\text { silica }\end{array}$ & $\begin{array}{l}\text { Cellulose tris-(3,5- } \\
\text { dimethylphenylcarbamate) }\end{array}$ & $150 \times 4.6$ & 3.0 \\
\hline Chiralpak IC & $\begin{array}{l}\text { Chiral } \\
\text { Technologies }\end{array}$ & $\begin{array}{l}\text { Fully porous } \\
\text { silica }\end{array}$ & $\begin{array}{l}\text { Cellulose tris-(3,5-dichloro- } \\
\text { phenylcarbamate) }\end{array}$ & $150 \times 4.6$ & 5.0 \\
\hline Chiralpak ID & $\begin{array}{l}\text { Chiral } \\
\text { Technologies }\end{array}$ & $\begin{array}{l}\text { Fully porous } \\
\text { silica }\end{array}$ & $\begin{array}{l}\text { Amylose tris-(3-chloro- } \\
\text { phenylcarbamate) }\end{array}$ & $150 \times 4.6$ & 5.0 \\
\hline Chiralpak IF & $\begin{array}{l}\text { Chiral } \\
\text { Technologies }\end{array}$ & $\begin{array}{l}\text { Fully porous } \\
\text { silica }\end{array}$ & $\begin{array}{l}\text { Amylose tris-(3-chloro-4- } \\
\text { methylphenylcarbamate) }\end{array}$ & $150 \times 4.6$ & 3.0 \\
\hline Chiralpak IG & $\begin{array}{l}\text { Chiral } \\
\text { Technologies }\end{array}$ & $\begin{array}{l}\text { Fully porous } \\
\text { silica }\end{array}$ & $\begin{array}{l}\text { Amylose tris-(3-chloro-5- } \\
\text { methylphenylcarbamate) }\end{array}$ & $150 \times 4.6$ & 3.0 \\
\hline
\end{tabular}


Table 2

558 Design of experiments

\begin{tabular}{|lccc|}
\hline & Final solvent percentage & Gradient time & Oven temperature \\
\hline$-\alpha$ & $60 \%$ & $3.0 \mathrm{~min}$ & $20^{\circ} \mathrm{C}$ \\
-1 & $64 \%$ & $3.8 \mathrm{~min}$ & $24^{\circ} \mathrm{C}$ \\
0 & $70 \%$ & $5.0 \mathrm{~min}$ & $30^{\circ} \mathrm{C}$ \\
+1 & $76 \%$ & $6.2 \mathrm{~min}$ & $36^{\circ} \mathrm{C}$ \\
$+\alpha$ & $80 \%$ & $7.0 \mathrm{~min}$ & $40^{\circ} \mathrm{C}$ \\
\hline
\end{tabular}

559

560

561

562

563

564

565

566

${ }^{*} \mathrm{ND}=$ Not determined

Table 3

Fractions analysis: collected masses and volumes, quality control for each fraction

\begin{tabular}{|l|l|l|l|l|}
\cline { 2 - 5 } \multicolumn{1}{c|}{} & Fraction 1 & Fraction 2 & Fraction 3 & Fraction 4 \\
\hline Collected volume (L) & 3.5 & 4.3 & 5.0 & 14.8 \\
Collected mass (g) & ND & 0.3 & 0.3 & 3 \\
\hline \multicolumn{5}{|c|}{ Fractions purity } \\
\hline API & $98.5 \%$ & $0.8 \%$ & ND & ND \\
Mono oxide 1 & $<1$ & $95.8 \%$ & $0.1 \%$ & ND \\
Mono oxide 2 & $<1$ & ND & $97.5 \%$ & ND \\
Di oxide & ND & $2.6 \%$ & $2.1 \%$ & $99.3 \%$ \\
\hline
\end{tabular}

567

568 
Fig. 1
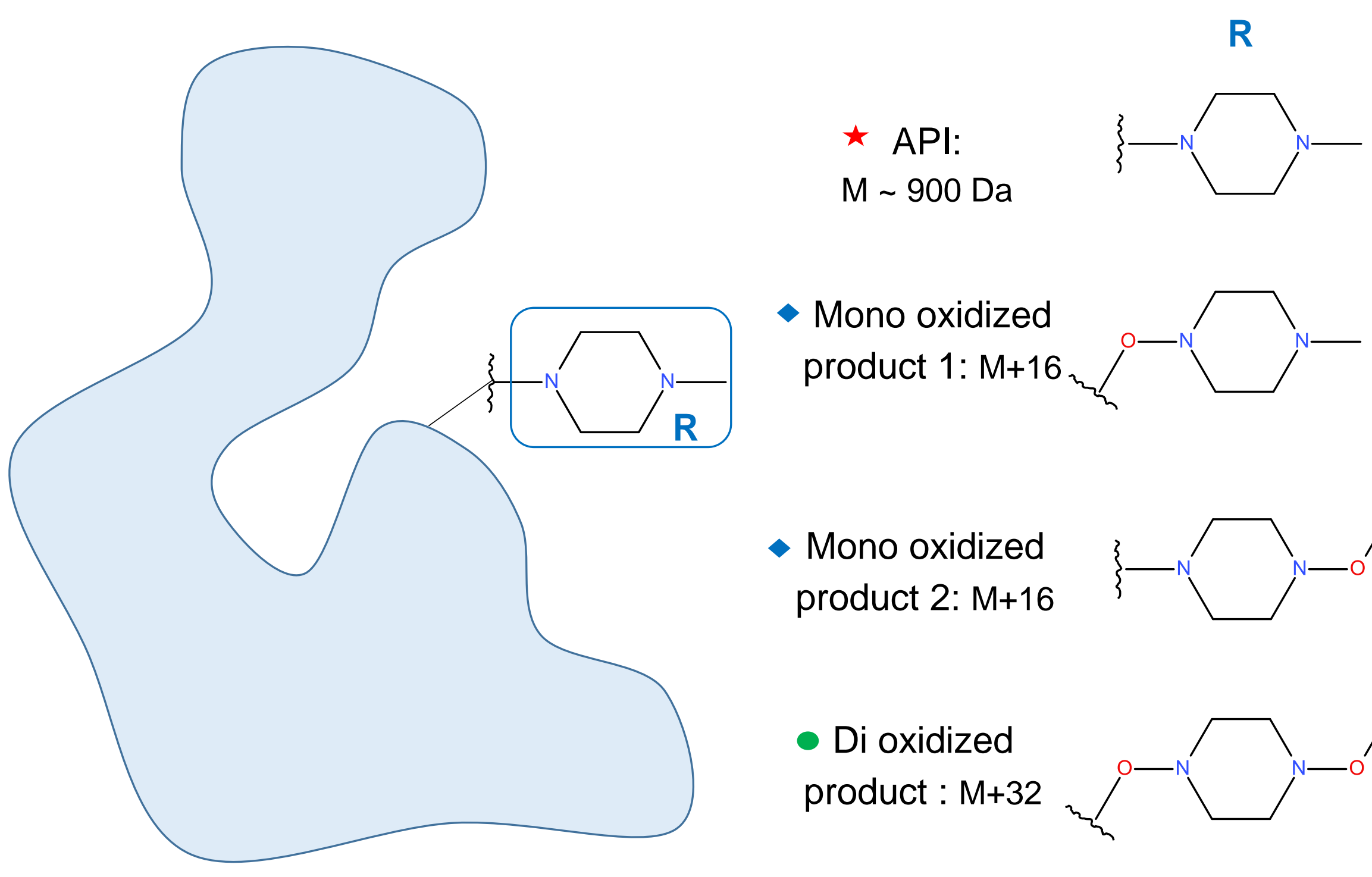

- Mono oxidized product 1: $\mathrm{M}+16$

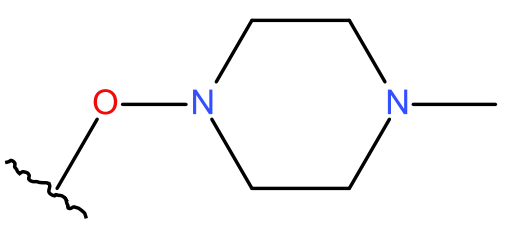

- Mono oxidized product 2: $\mathrm{M}+16$

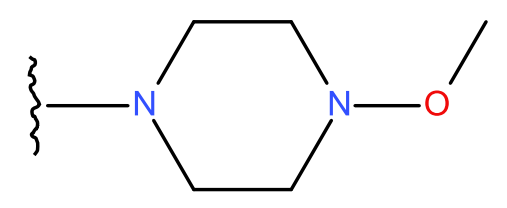

- Di oxidized product : M+32

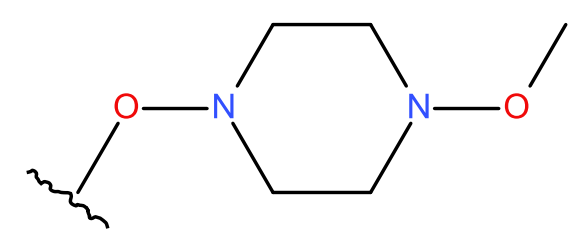


Fig. 2

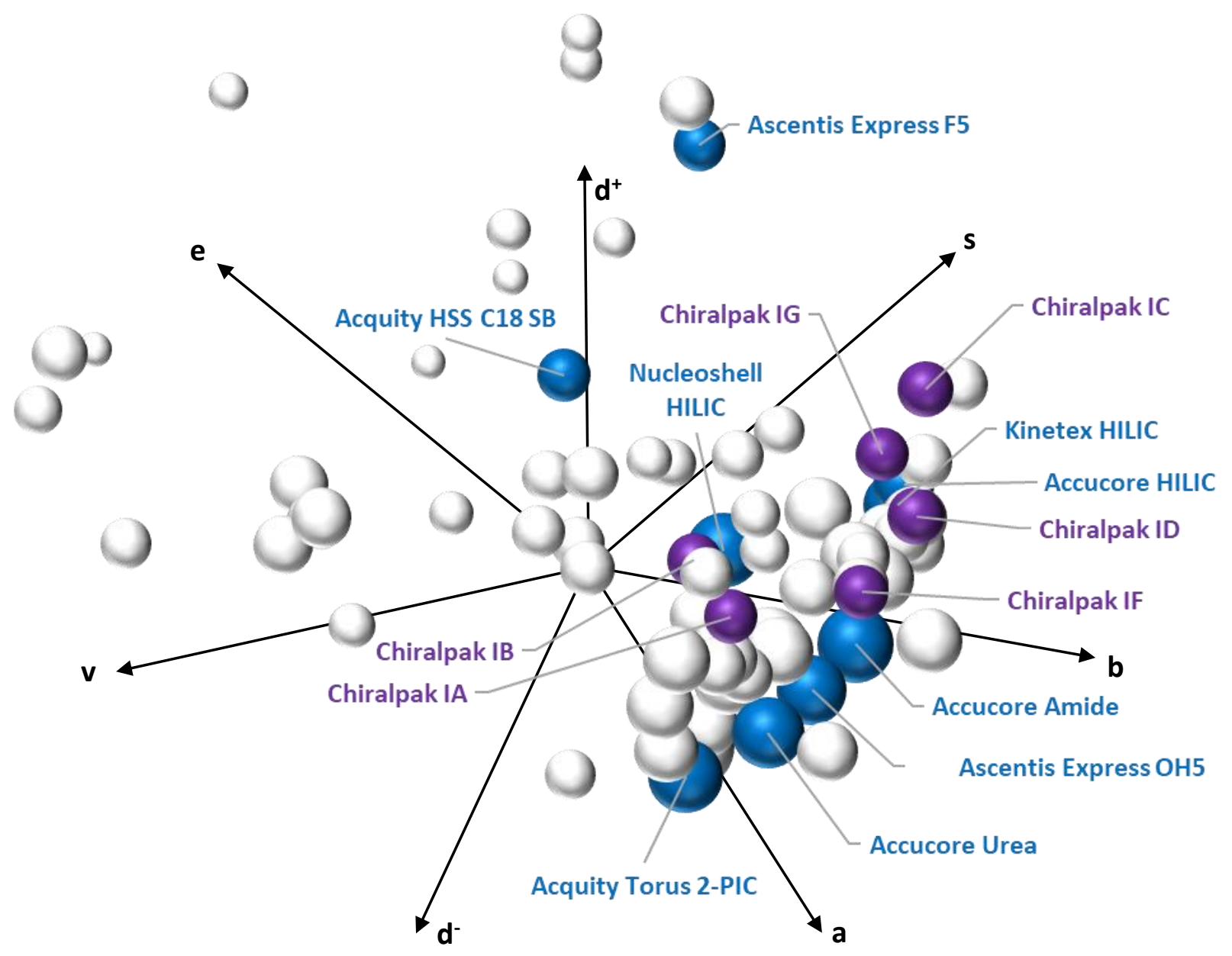


Fig. 3

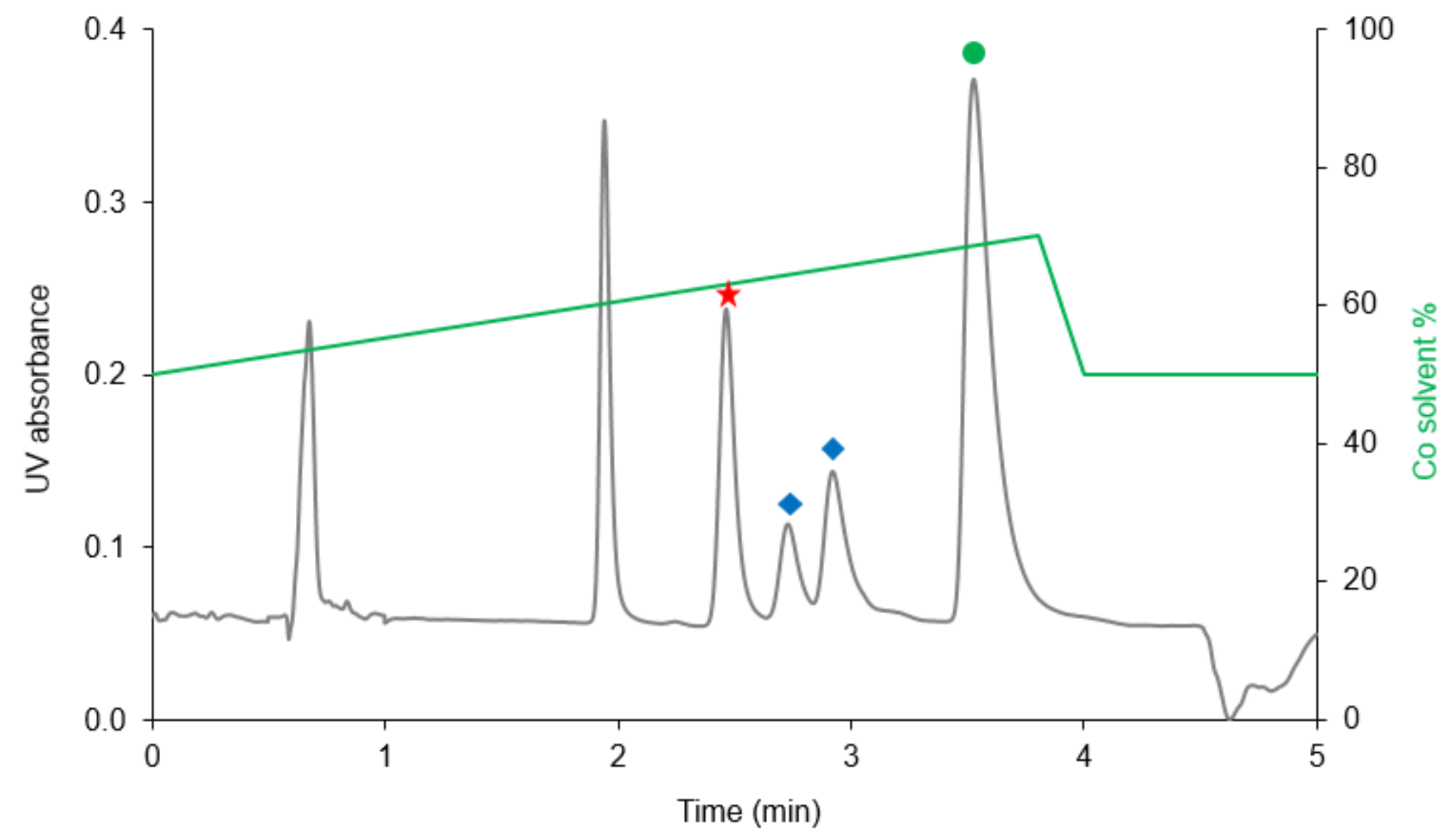


Fig. 4

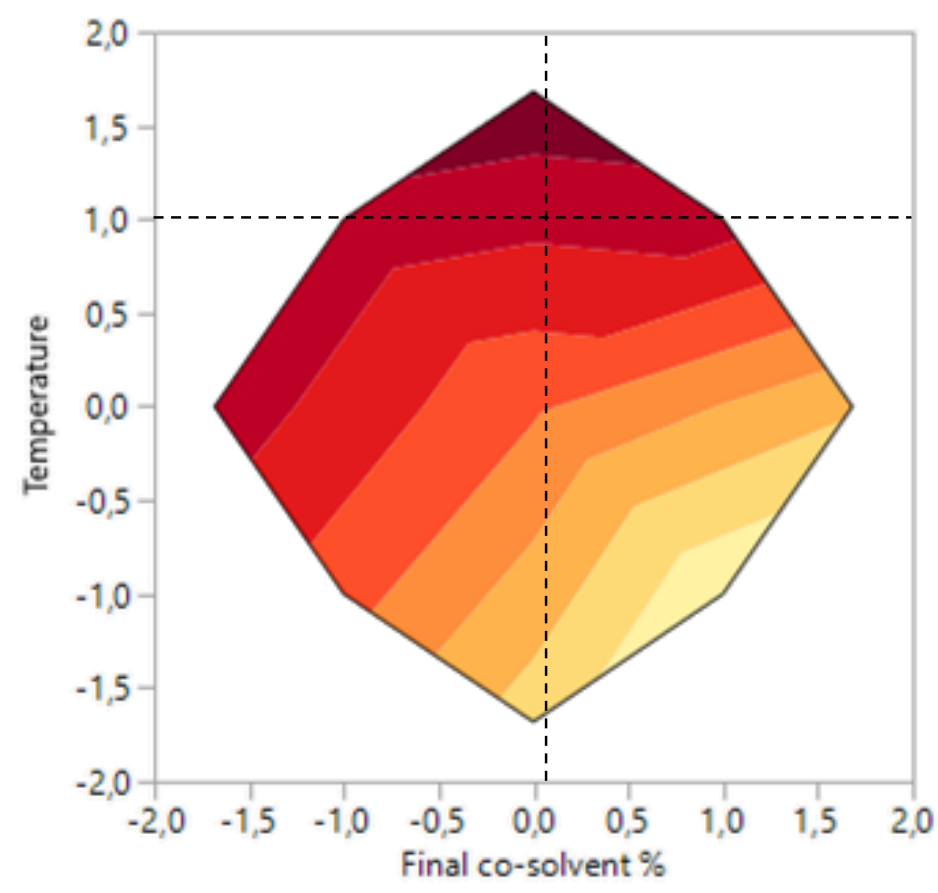

s4-3

$$
\begin{aligned}
& <-0,070 \\
& <-0,060 \\
& <-0,050 \\
& <-0,040 \\
& <-0,030 \\
& <-0,020 \\
& <-0,010 \\
& >-0,010
\end{aligned}
$$

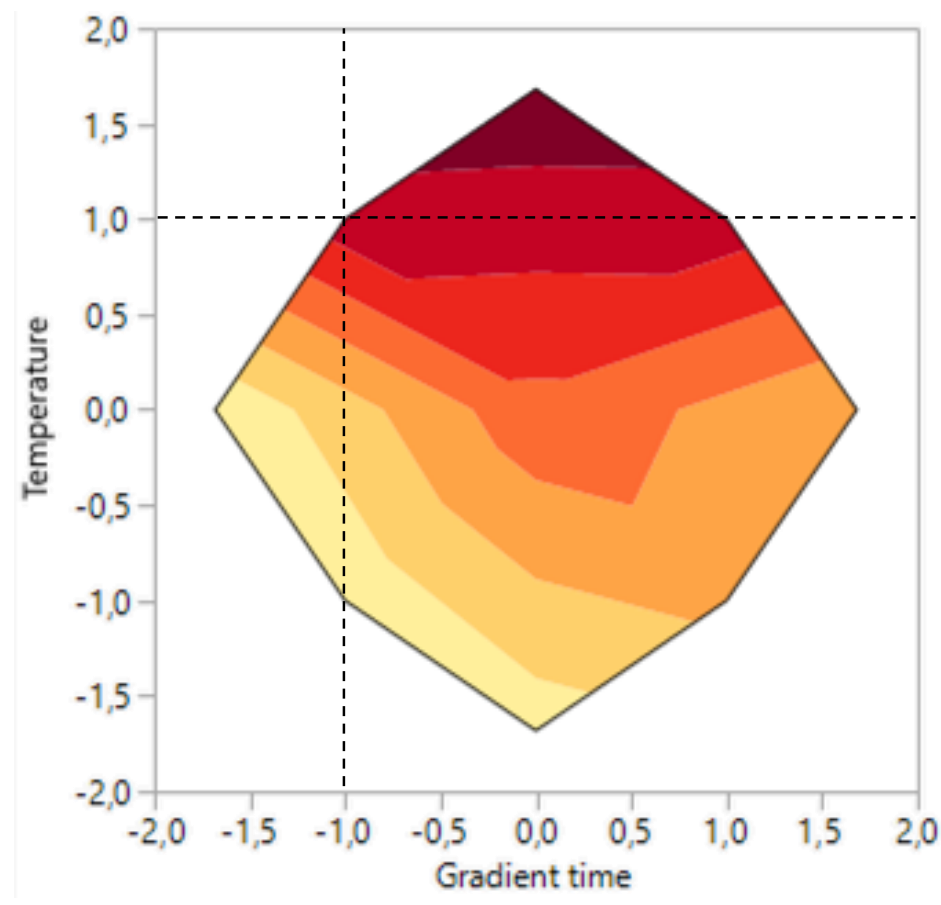

s4-3

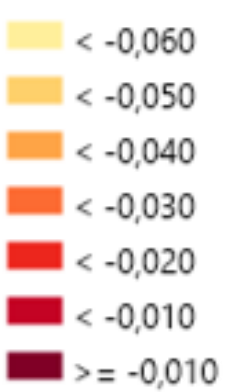


Fig. 5

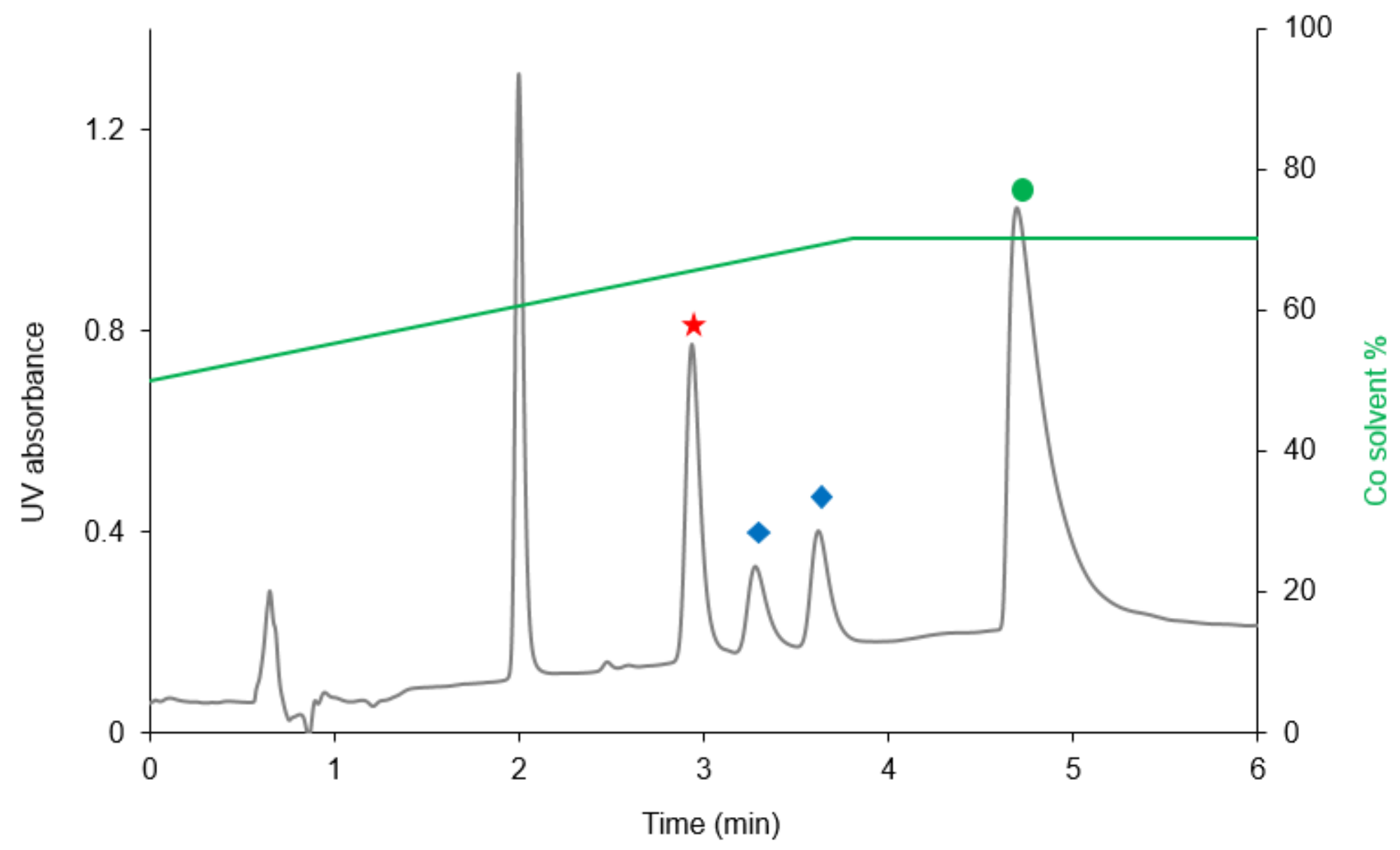


Fig. 6

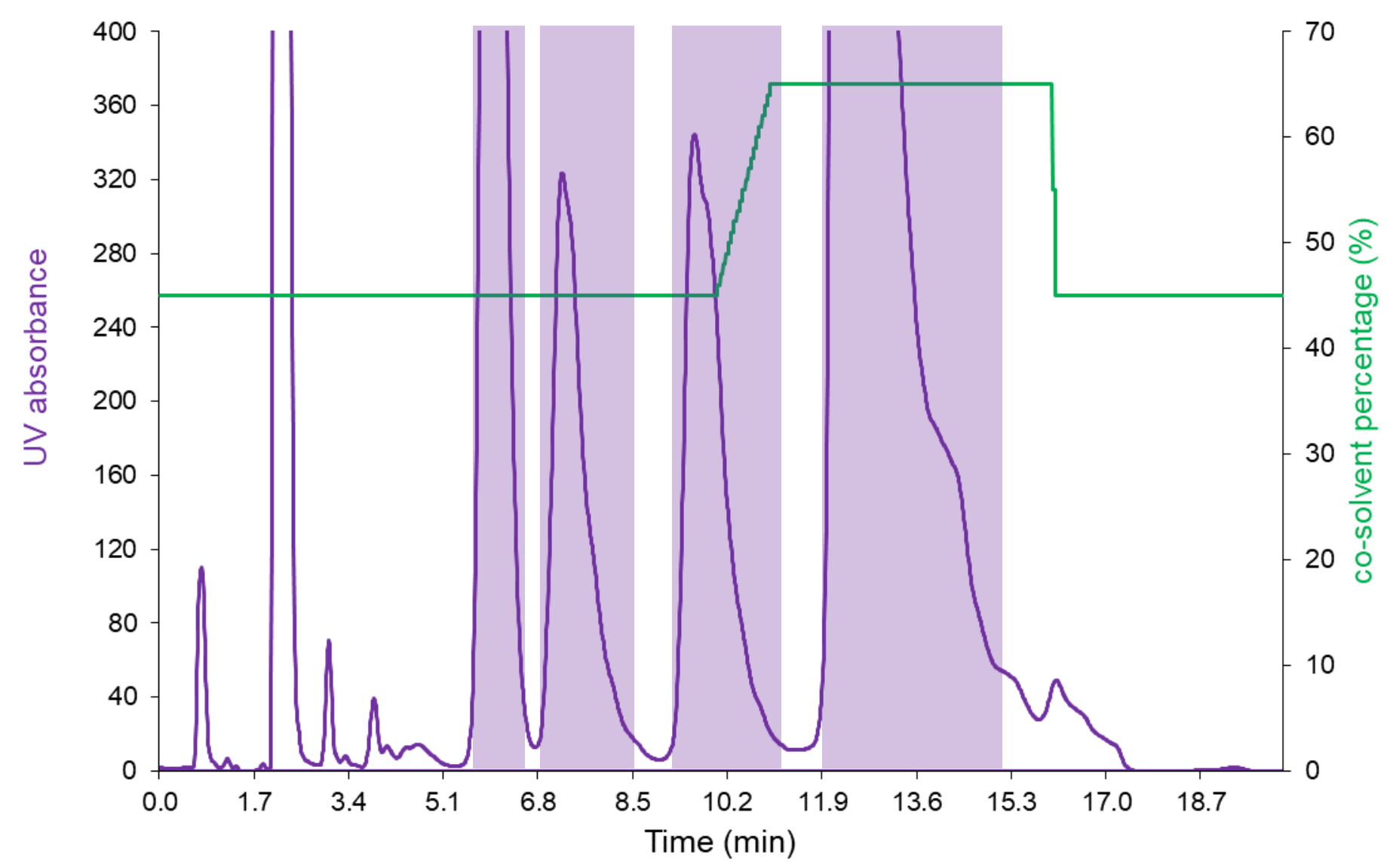




\section{Otwaction Supercritical fluid chromatography}

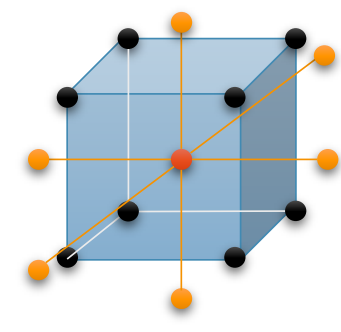

Design of experiments

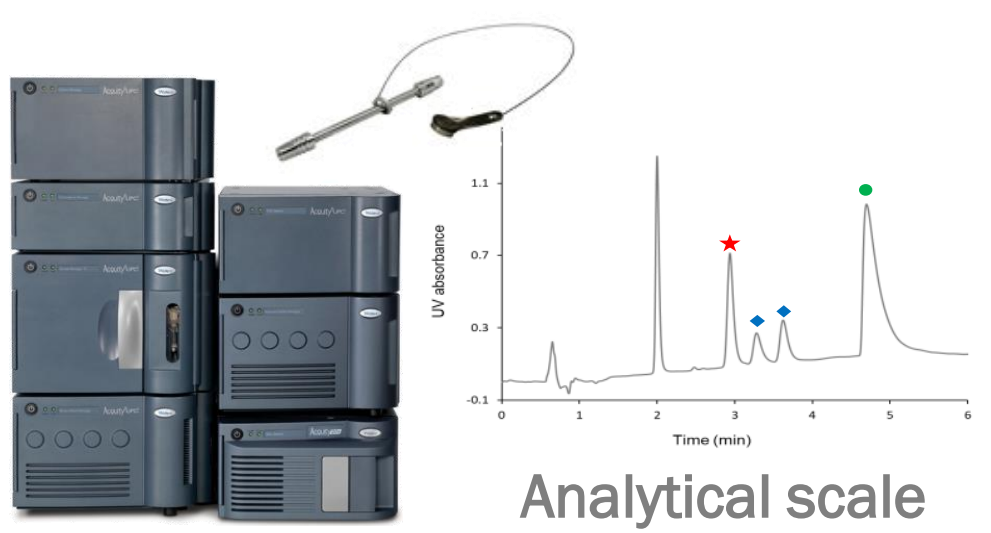

\section{Method/optimization}

Scale-up

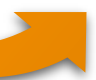

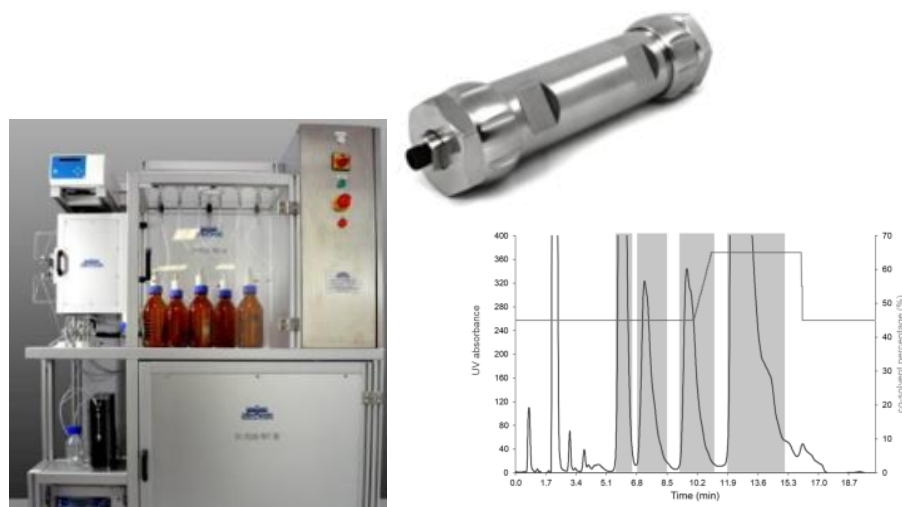

Preparative scale 